〔第46回総会シンポジウム〕

\title{
放射線機器を用いた血流計測の現状と将来
}

\author{
座長 花 山 正 行 (大阪大学医学部附属病院) \\ 演者 春 日 敏 夫（信州大学医学部附属病院）赤 井 喜 徳 (大阪大学医学部附属病院) (原稿未着) \\ 相 沢 康 夫 (秋田県立脳血管研究センター) 西 村 恒 彦 (国立循環器病センター)
}

\section{IADSA による頸動脈血流量測定}

春 日 敏 夫

信州大学医学部附属病院放射線部

Key words: Blood flow measurement, Blood vessel volume, Mean transit time, DSA image analysis.

\section{CAROTID BLOOD FLOW MEASUREMENT BY IADSA}

\section{Toshio Kasuga}

Department of Radiology, Shinshu University, School of Medicine

\section{Summary}

The author reports on current trial methods, and examines technical problems concerning blood flow measurement by DSA.

Precision of this method depends on the measurement of the blood vessel intra-volume and mean transit time.

For the measurement of the blood vessel intra-volume using an amplitude image the diameter of the blood vessel was measured as the Full Width Half Maximum of the profile curve in the transaxial direction of the blood vessel. Diameters of short length sections of the blood vessels were calculated, and then the mean diameter of the blood vessel was determined. Blood vessel volume in the ROI was calculated geometrically, and geometrical enlargement was corrected depending on the depth of the blood vessel. Measurement error was decreased by the use of this averaging method.

For the measurement of the mean transit time, the time lag between the two ends of the ROI was measured as a linear approximation of the relationship between distance and time, using time parameters of the above short length sections.

On the graph, measurement error was decreased by the exclusion of the areas of turbulant blood flow caused by the shape of blood vessel itself, and those caused by the injection of contrast medium from the tip of the catheter.

As for the time parameters, the phase value of the first Fourier transform of the timedensity curve and the peak time of the fitted Gamma-function curve, were adopted for reasons of accuracy compared to other examined parameters. For these two parameters, automated processing, to detect the rise point of the time-density curve, improved the measurement precision of these two time parameters.

DSA による血流量測定法の報告 ${ }^{1-14)}$ は多い。しかし， 臨床利用に耐えうる精度の絶対量測定法は，いまだ確立 されていないように思われる．測定法を大別すると，血
管容積 $(V)$ と 2 点間を通過する平均通過時間 (MTT) を測点し，これから血流量 $(\mathrm{F})$ を $\mathrm{F}=\mathrm{V} / \mathrm{MTT}$ を求め る方法 ${ }^{1-3,5-10)}$ と，血管像の局所に関心領域（ROI）を設 
定して，この時間濃度曲線の下部面積が流量に比例する と考えるダイリューションテクニック ${ }^{11-14)}$ がある. 後者 は，流速が異なると曲線下部面積が流量に比例せず，物 理的な問題点もあり，絶対量の測定は困難と考える.わ れわれは，前者について相対的血流量測定法を報告した がここでは，絶対量測定における血管客積と MTT 測 定について，その技術的問題点を中心に考察し，その試 行による対応法を述べ，若干の結果を記述し，さらに今 後の可能性と限界について簡単に触れたい.

\section{1. 血管容積測定の問題点と我々の技術 的対応}

DSA 像から血管容積を幾何学的に測定 ${ }^{1-4,7-8,10)}$ する 場，まず，測定の対象となる血管の選択が重要になる。 他の血管との重複が少なく, 分枝, 屈曲, 変形が少なく, かつ，細い血管ほど誤差が大きくなるために内径 3 $\mathrm{mm}^{18,199)}$ 以上の太い血管であることが必要と思われる. 本稿では，総頸動脈と内頸動脈とを対象とし，分枝の多 い外頸動脈を対象外とした。また，DSA 撮影における血 管の幾何学的拡大率の補正が必要であるため, 血管が撮 影台に平行して走行していることが望しく，検查時に深 度が推定できる血管が選択される，次に，血管断面を円 と仮定し，その内径をDSA 像から測定する場合，広範囲 に造影剤が充満され，境界鮮明な DSA 像が必要である， Fig. 1 の如く, 経時的収集像 (上段 2 列)では充満造影範 囲が狭く，加算像（下段左）では境界鮮明ではない.S/ $\mathrm{N}$ を向上させるため像加算が必要であるが，心拍動の影 響による血管の動きが境界の不鮮明化と測定誤差を生ず る.われわれは，これらの技術的解決策として一次フー リ工変換 ${ }^{15-17)}$ による amplitude image (下段右)を用い ることをすでに提案 ${ }^{18,19)}$ した。ささらに, DSA 収集像のマ トリックスサイズが測定精度に影響する。例えば，9イ ンチのII視野，256×256マトリックス（ピクセルサイズ $0.86 \mathrm{~mm}$ ) において, 内径動脈を想定し血管径 $7 \mathrm{~mm}$ で 測定血管範囲の長さ $2 \mathrm{~cm}$ を仮定し, 血管内径の測定誤 差が 2 ピクセル分だけ生じたとき，容積測定誤差は $30 \%$ 以上に達する，マトリックスサイズを小さくした，高精 度な計測を必要とするが，これには限界がある，われわ れは, 総頸動脈, 内頸動脈では, 約 $2 \mathrm{~cm}$ 以上の測定範囲 (ROI 長)を設定できることから, Fig. 2 の如く ROI を設 定し， $\mathrm{m}$ 行の血管径方向のプロフィール曲線の半值幅か ら内径を求め, これを加算平均化する統計的な誤差低減 策を行った。

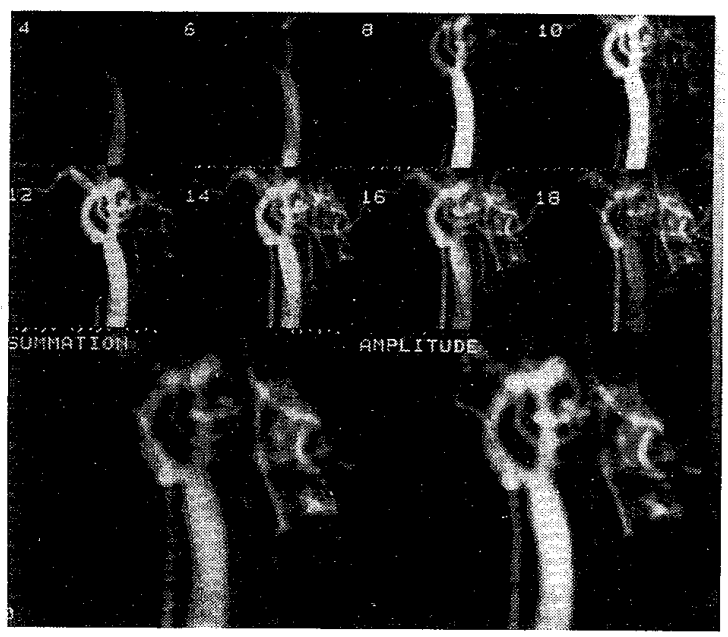

Fig. 1

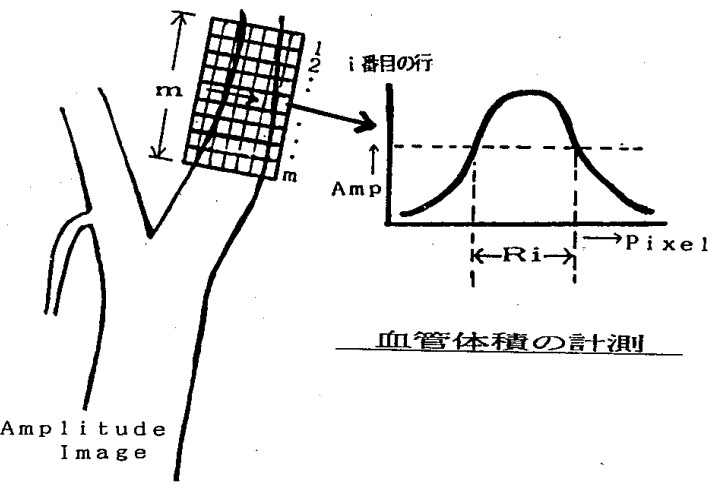

Fig. 2

\section{MTT 測定の問題点と我々の技術的 対応}

造影㣂は，比重，粘段など物理的性状が血液と異なる ために，血管内で層流が生じ，また，流れの道程では拡 散が生ずる。さらに，血管内の流速は三次元的に異なり， 血管の形態によって局所的な血流の乱れを生ずる ${ }^{21)}$.こ れらは測定血管の時間濃度曲線の影響を与え測定誤差の 因子となる．また，心拍動の影響も血管上の測定部位に よって異なり ${ }^{10)}$, 時間的な流速変化は心臓からの距離に よって異なる.これらの流体力学的な影響を少くするに は, まず, 同一血管上で, 近距離の 2 点間で, 造影剤ボ ーラスの通過時間を測定する必要があろうと思われる。 一方，DSA 像の収集間隔（サンプリング間隔）は，現時 点の装置では33 msec/frame 以下の高速収集が困難で あるため, ある程度の 2 点間距離は必要である。さらに, DSA 像の $\mathrm{S} / \mathrm{N}$ も, 時間濃度曲線から時間パラメータを 求める際の誤差因子であり，われわれの装置では 5 ピク セル以上の領域が必要と考光られた。

われわれは，Fig. 3 のように ROI を設定し， ROI マト 


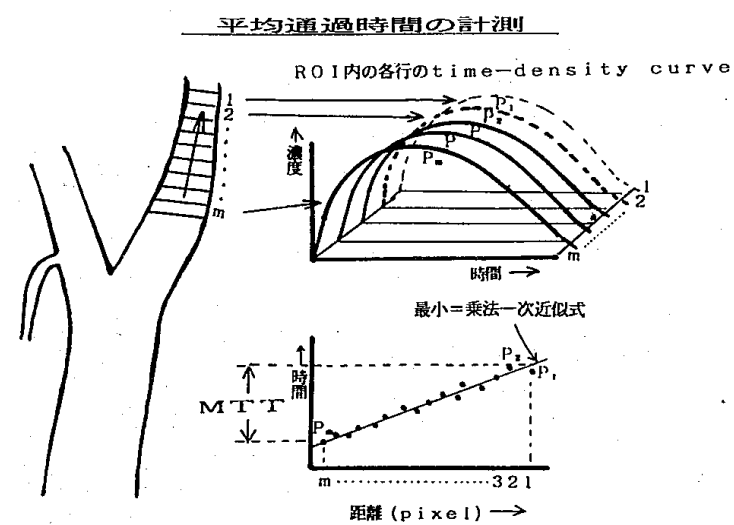

Fig. 3

リックスの各行（m行）の小区画の時間濃度曲線から時 間パラメータを求め, このパラメータの時間と距離との 関係を最少二乗法で一次近似し，この近似直線から ROI の片端（m行）と他端（1 行）との時間差を MTTとし た ${ }^{18,19)}$. また，この時間パラメータのグラフ表示におい て, 直線関係が成立しない部位は, 血流が乱れ局所的に 流速が異なる部位として人間の判断で除外し, 再度, 一 次近似を行う手法をとった (Fig. 9, 14 参照). 時間パラ メータとしては, 時間濃度曲線の(1) ピーク $5,6,8,10)$, (2)重

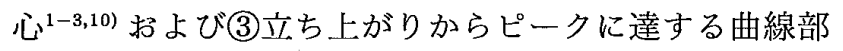
分の変曲点 ${ }^{10)}$ (微分曲線の最大值点：以下変曲点と記

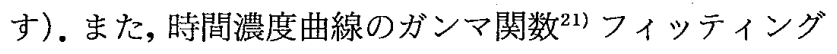
カーブの(4)ピーク, (5)重心および6)変曲点, さらに, 時 間濃度曲線の一次フーリエ変換による(7)位相值 ${ }^{18,19)} に つ$ いて検討した.この際, ガンマ関数フィッティングと一 次フーリ工変換は, 時間濃度曲線が造影剤によって立ち 上がる部分を自動判定し，それ以後のデータを扱った。 例えば, 一次フーリエ変換の場合, Fig. 4 に示すように, 曲線の立ち上がりを判定させ，位相值を求めた。すなわ

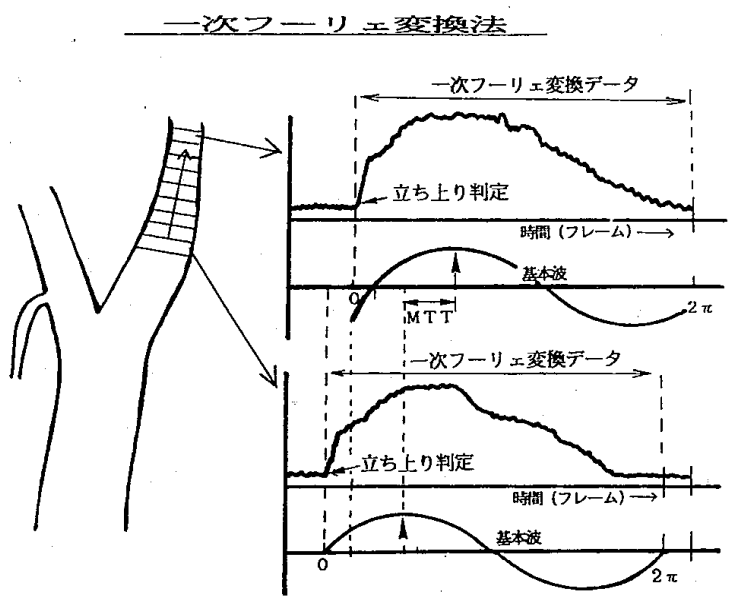

Fig. 4
ち, MTT は ROI 両端間の立ち上りの時間差と位相差の 加算値とした。 また，位相值はラジアン単位で求まるが, 処理データ数（サンプリングフレーム数）を一定にして 基本波の時間を同一にすることにより実時間（秒単位） に換算した ${ }^{18,19)}$.

\section{3. 我々の試行法による結果}

基礎実験 1 ：内径 $7 \mathrm{~mm}$ のビニールチューブに拍動 流ポンプ（HARVARD-1421）を結合し，チューブ片端 から $10 \mathrm{ml} / \mathrm{stroke} / \mathrm{sec} の$ 速度で水を流し, $33 \mathrm{msec} /$ frameのサンプリング間隔で $512 \times 512$ マリリック DSA 像を経時的に収集した.この際，Fig. 5 の如く，チ ューブ他端から流出した水量とチューブ実測内径から計

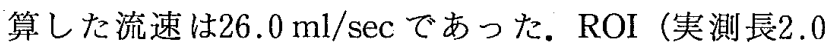
$\mathrm{cm})$ は 2 個所設定し, 計算された真の ROI 内チューブ容 積は $0.763 \mathrm{ml}$ であり, ROI 両端間の真の MTT は76.3 msec であった。本法による測定では，2 個所の ROI 内テ ューブ容積は, それぞれ $0.765 \mathrm{ml} と 0.750 \mathrm{ml}$ であり, 真 のチューブ容積との誤差は少なかった。また，上記の各 時間パラメータについて本実験での MTT 测定を奏施 したが，本稿では時間濃度曲線のピーク時間 (PT) と， ガンマ関数フィッティングカーブのピーク時間 (GP) おう よび変曲点時間 (GD), 一次フーリエ変換の位相值 (FT) での結果を示す. PT と GD では真の水流量 $10 \mathrm{ml} / \mathrm{sec} に$ 対し誤差が大きく, FTでは $9.2 \mathrm{ml} / \mathrm{sec} 9.3 \mathrm{ml} / \mathrm{sec}$ で, $\mathrm{GP}$ では $10.8 \mathrm{ml} / \mathrm{sec}, 11.5 \mathrm{ml} / \mathrm{sec}$ で, 他の時間パラメー 夕に比較して誤差が少なかった。

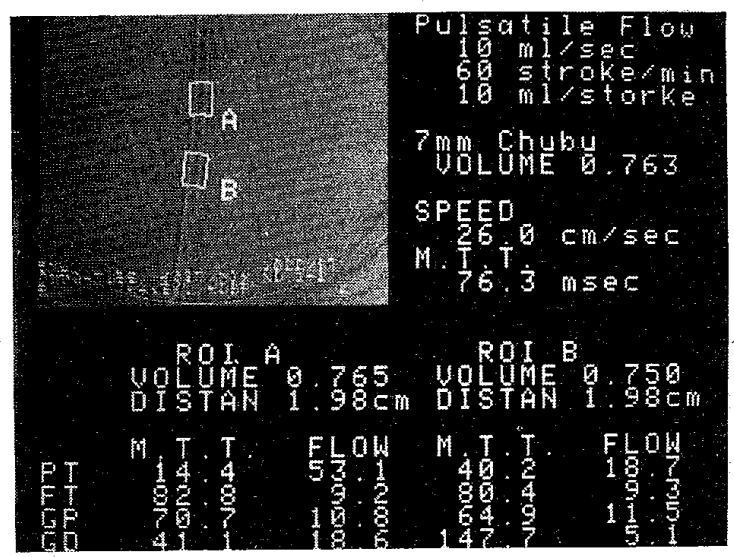

Fig. 5

基礎実験 2 : 上記と同様な実験であるが, 内径 $7 \mathrm{~mm}$ のゴム管を用いて，流速を $5 \sim 15 \mathrm{ml} / \mathrm{sec} て ゙$ 変化させた 結果を Fig. 6に示す。実測計算による真の流量 Measured flow volume と, 本法での測定計算による Caluculated flow volume との誤差は最大15\%であった. 
また, 流速 (flow speed が速いほど誤差が大きく, 13〜26 $\mathrm{cm} / \mathrm{sec}$ の範囲では $9 \%$ \%下であうた。

臨床例 1 (HT, 今, 64)：内頸動脈狭窄例で, 内膜剝 離術前後に本法を施行した症例であり，Fig. 7 左に術前， 右に術後の DSA 像を示す. 術前の測定結果 (Fig. 8) で は, 総頸動脈が FT で $2.3 \mathrm{ml} / \mathrm{sec}, \mathrm{GP}$ で $2.4 \mathrm{ml} / \mathrm{sec,} \mathrm{内}$ 頸動脈が FT で $1.4 \mathrm{ml} / \mathrm{sec}, \mathrm{GP}$ で $1.4 \mathrm{~m} / \mathrm{sec}$ の結果を示 した.FTと GP の測定值に差は少なかったが，総頸動 脈, 内頸動脈とも著しい血流低下值を示した. Fig. 9 はこ の際の総頸動脈における時間パラメータのグラフ表示で, 横軸の左方から右方端は, ROI 上端から下端に対応す る.この関係を前述の如く最小二乗法で一次近似したが, グラフ表示上で ROI 下方の直線関係を示さない部分が 明らかである。この部位は, カテーテル先端からの造影 剤射出部に一致し, 乱流の存在が認識できる。この部分

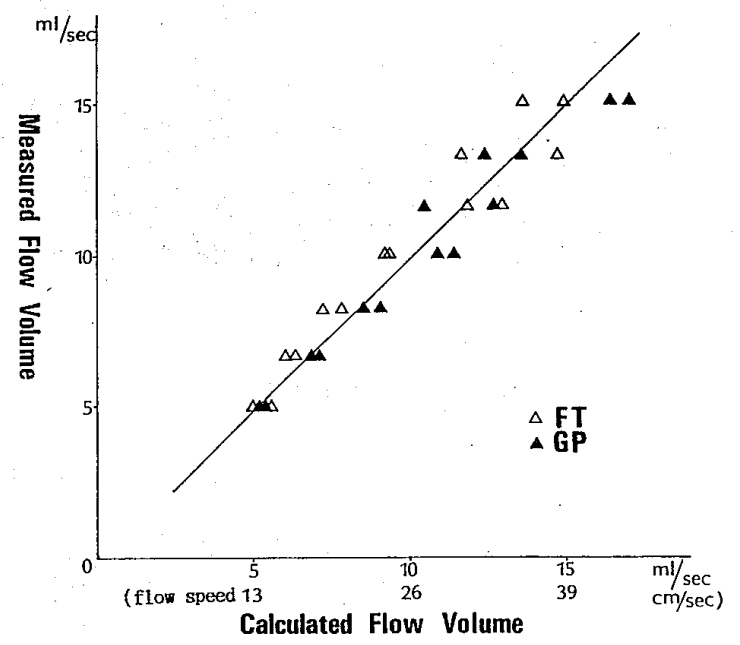

Fig. 6

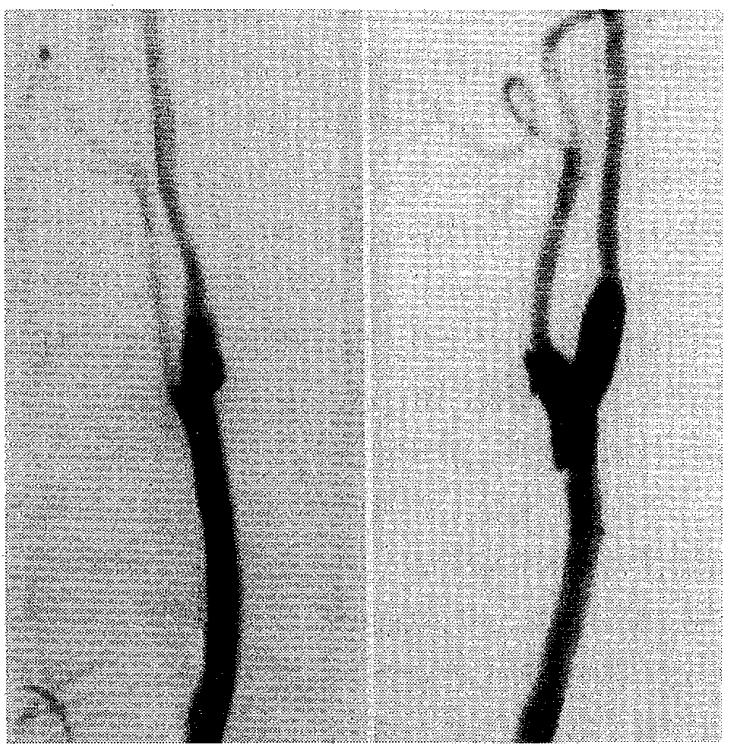

Fig. 7
を除外し FT, GP, GD について改めて一次近似させ，各 の直線から ROI 両端間の時間差を求めた様子を示した。 図中の $\mathrm{K}$ は直線の勾配， $\mathrm{r}$ は相関係数を示す.Fig. 10 は，同症例の術後の測定結果で，総頸動脈ではFT で7.3 $\mathrm{ml} / \mathrm{sec}, \mathrm{GP}$ で7.0 ml/sec, 内頸動脈では FT で3.1 ml/ sec, GP で2.7 ml/sec を示し, 総頸動脈, 内頸動脈とも に血流の増加を示した，また，この結果で外頸動脈の著 明な血流増加が推定されるが，これはDSA 像のシネモ ード表示で観察された所見とも一致した.(Fig.7 右).

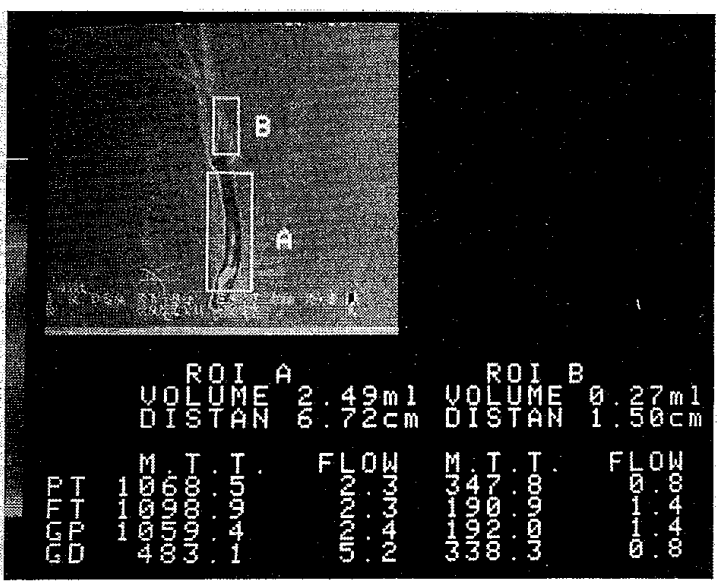

Fig. 8

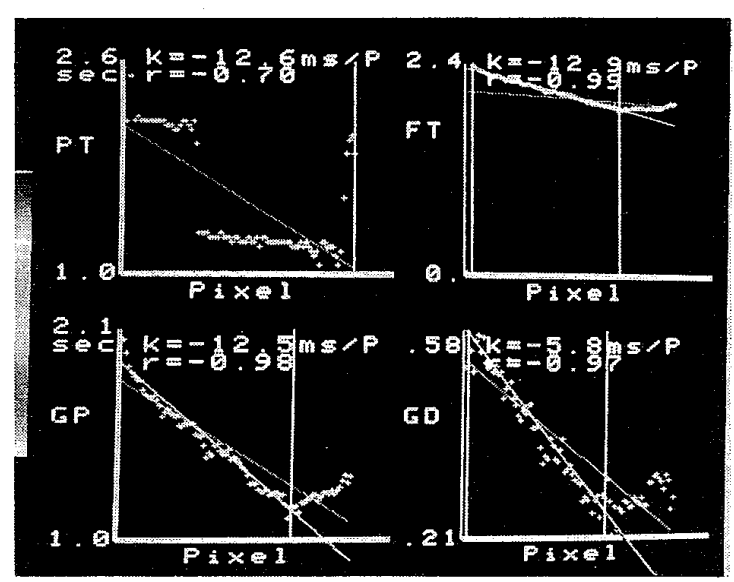

Fig. 9

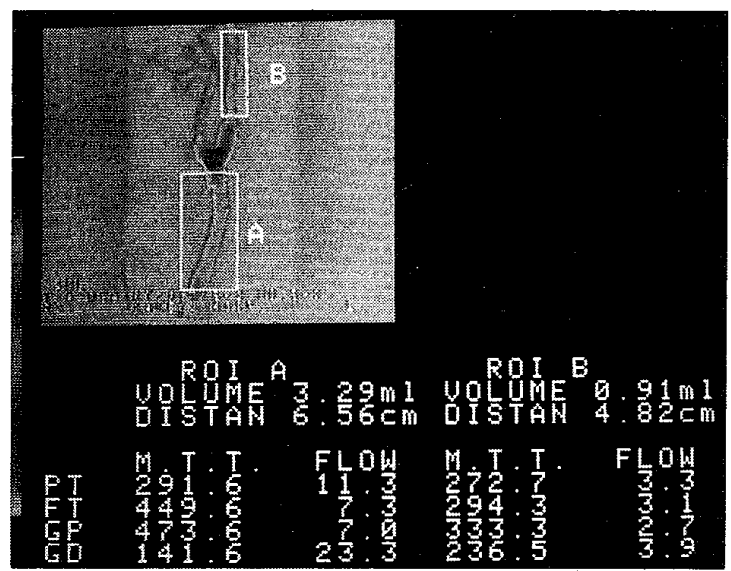

Fig. 10 
症例 2（YT, 合，42）：内頸動脈狭窄例で内膜剥離術 前後に本法を施行した症例で, Fig. 11 の左に術前，右に 術後の DSA 像を示す.また, Fig. 12 は術前の測定結果 で, 総頸動脈では FT で6. $0 \mathrm{ml} / \mathrm{sec}, \mathrm{GP}$ で6.9 ml/sec, 内頸動脈では FT で1.5 ml/sec，GP で1.6 ml/sec の血 流量值を示し，とくに内頸動脈での低下が認められた. Fig. 13 は術後の測定結果で, 総頸動脈ではFT $\mathrm{ml} / \mathrm{sec}, \mathrm{GP}$ で $11.4 \mathrm{ml} / \mathrm{sec}$ と大きく異なり, 内頸動脈で はFT で5. $4 \mathrm{ml} / \mathrm{sec}, \mathrm{GP}$ で $5.8 \mathrm{ml} / \mathrm{sec}$ と術前に較べ著 明な血流量増加を示した. 総頸動脈でFT と GP とで血 流量値に大差が認められた原因はMTT 值の問題であ り，時間パラメータのグラフ表示（Fig. 14）で認められ るように, GPより FT の方がカテーテル先端からの造 影剂射出による乱流の影響が大きく，FTの精度が悪か ったことによると思われた。

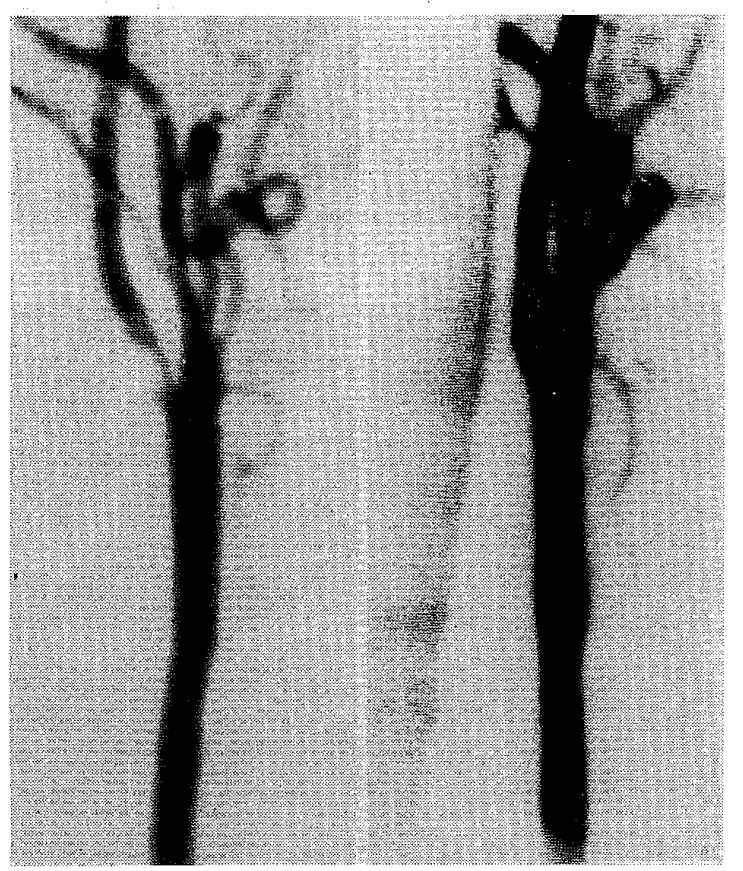

Fig. 11

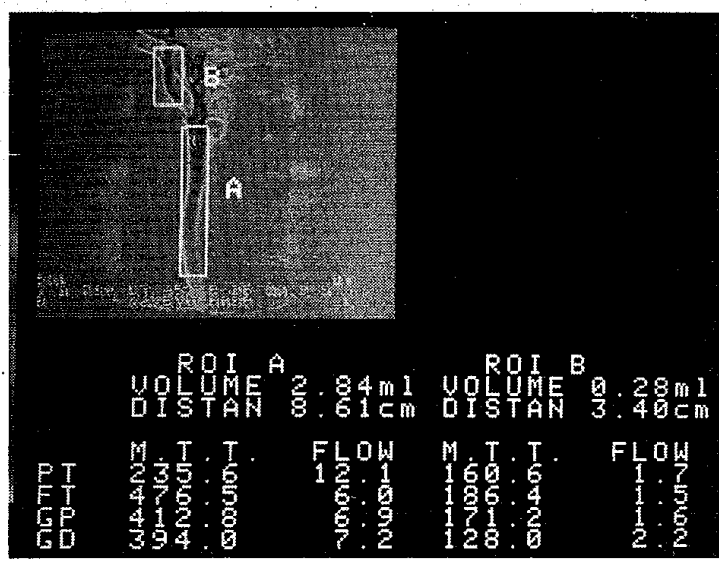

Fig. 12

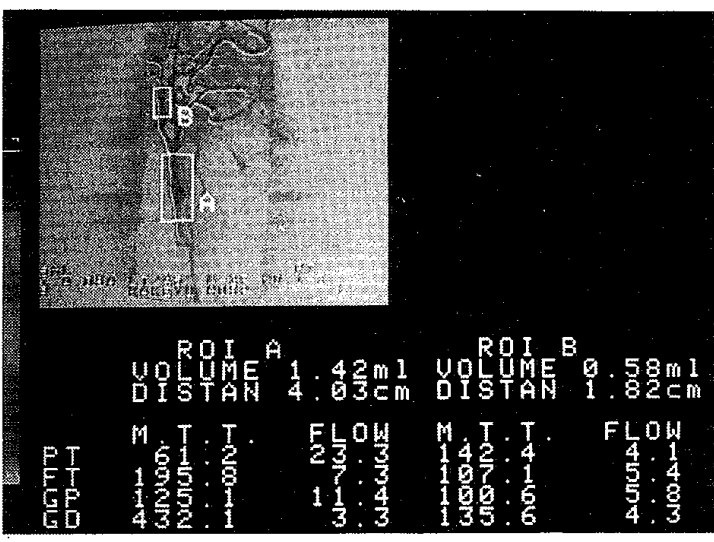

Fig. 13

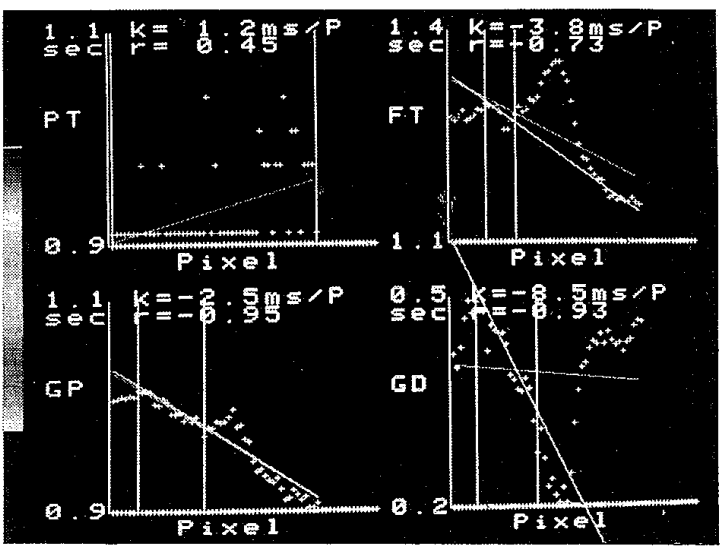

Fig. 14

\section{4. 今後の可能性と限界}

DSA による血流量測定には, 前述のように造影剂の流 体力学的な問題, 血管内の三次元的な流速の違い, 血管 の形態による乱流, 心拍動の影響, DSA および解析装置 の問題などにより测定精度に限界がある.とくに, 局所 の時間濃度曲線は, 心臓に近い大血管と本稿で検討した 頸動脈とでは大きな違いがあり，本法での時間パラメー 夕は胸部大動脈の血流量測定には適用できないと思われ る.また, 造影剤のボーラス性の悪いIVDSA では, 測定 精度が期待できないと考える，われわれの試行では，臨 床例において測定精度の確認が得られていない.しかし， 基礎実験 ${ }^{18,19)}$ 加ら推定して, 平均血管容積, 平均通過時 間の測定精度向上により，臨床利用に耐えうる測定精度 は期待できる. 今後, 超音波, MRI など他モダリティで の測定技術の進歩と併せ評価されるべきであろうが，対 象とする血管に適応した処理法の開発により血管造影の 画像搒断に絶対定量情報を加えうると思われる。

(稿を終るにあたり,紙面の都合で本シンポジウムで報 告した一部を省略したことと，カラーモニター像をモ， クロ写真で揭載したことをお許しいただきたい。また， とくに御協力いただいた鹿教湯病院の石合知恵技師, 座 
長ならびに技術学会実行委員の諸先生に深謝の意を表し ます)。

\section{文献}

1) Rutishauser W, Noseda G, Bussmann WD: Blood flow measurement through single coronary arteries by roentgen densitometry; part 2 . Right coronary artery flow in conscious man. AJR 109, 21-24, 1970.

2) Smith HC, Sturm RE, Wood EH : Videodensitometric system for measurement of vessel blood flow, paticularly in the coronary arteries, in man. Am J Cardiol 32, 144-150, 1973.

3) Rosen L, Silverman NR: Videodensitometric measurements of blood flow using crosscorrelation techniques. Radiology 109, 305-310, 1973.

4) Kruger RA : Estimation of the diameter of and iodine concentration within blood vessels using digital radiography devices. Med Phys 8, 652$658,1981$.

5) Bursch JH, Hahne HJ, Brennecke R, Gronemeier $D$, et al: Assessment of arterial blood flow measurements by digital angiography. Radiology 141, 39-47, 1981.

6) Klingensmith WC: Regional blood flow with first circulation time-inducator curves; a simplified, physiologic medthod of interpretation. Radiology 149, 281-286, 1983.

7) Serruys PW, Reiber JHC, Wijns W, et al : Assessment of percutaneous transluminal coronary angioplasty by quantitative coronary angiography ; diameter versus densitometric area measurements. Am J Cardiol 54, 482-488, 1984.

8) Forbes G, Gray JE, Felmel JP : Phantom testing of peripheral artery absolute blood flow measurement with digital arteriography. Invest Radiol 20, 186-192, 1985.

9) Kruger A, Bateman W, Liu Y, et al : Blood flow detemination using recursive processing : A digital Radiographic method. Radiology 149, 293298, 1983.

10) Helntzen PH: Digital angiocardiography. Cardiac imaging and image processing, 239-279,
McGrow-hill book company, New York, 1986.

11) Lantz BMT, Dublin AB, McGahan JP, et al: Assessment of cerebral blood flow in man by video dilution technique; a preliminary report. Invest Radiol 16, 181-187, 1980.

12) Lantz BMT, Foerster JM, Link DP, et al: Regional distribution of cardiac output; normal values in man determined by video dilution technique. AJR 137, 903-907, 1981.

13) Foerster JM, Link DP, Latz BMT, et al: Measurement of coronary reactive hyperemia during clinical angiography by video dilution technique. Act Radiol 22, 209-216, 1981.

14) Lantz BMT: Video dilution technique; a radiological approach to hemodynamics. Digital image processing in Radiology, 137-157, 1985, Willams \& Wilkins, Baltimore, London.

15) Adam WE, Tarkowska A, Bitter F, et al : Equilibrim (gated) radionuclide ventriculography. Cardiovasc Radiol 2, 161-173, 1979.

16) Vos PH, Vossepoel AM: Functional images to describe the contractility of the heart in gated blood pool studies. Medinfo 80, 1121-1125, 1980.

17) Putishauser W, Bussmann WD, Noseda G, et al : Blood flow measurement through single coronary arteries by roentgen densitometry; part 1 . A comparison of flow measured by a radiologic technique applicable in the intact organism and by electromagnetic flowmeter AJR 109, 12-20, 1970.

18）矢野今朝人, 春日敏夫, 丸山二三男：DSA による相 対的な血流量測定法の開発。日放技学誌, 46(6), 679 $-689,1987$.

19）春日敏夫，曾根脩輔，矢野今朝人：DSA による血管 内血流状態の可視化像と相対血流量計測. 日本医放 会誌，48(4)，480-496，1988.

20) Fukushima T, Azuma T: The horseshoe vortex ; a secondary flow generated in arteries with stenosis, bifurcation, and branchings. Biochemology 19, 143-154, 1982.

21) Davenport $\mathrm{R}$ : The derivation of the Gammavariate relationship for tracer dilution curve. $\mathrm{J}$ Nucl Med 24, 945-948, 1983. 